\title{
RESEARCH
}

Open Access

\section{Can financial payments incentivize short- term smoking cessation in orthopaedic trauma patients? Evidence from a discrete choice experiment}

Dana Alkhoury', Jared Atchison², Antonio J. Trujillo³, Kimberly Oslin², Katherine P. Frey', Robert V. O'Toole², Renan C. Castillo ${ }^{1}$ and Nathan N. O'Hara ${ }^{2^{*}}$

\begin{abstract}
Background: Smoking increases the risk of complications and related costs after an orthopaedic fracture. Research in other populations suggests that a one-time payment may incentivize smoking cessation. However, little is known on fracture patients' willingness to accept financial incentives to stop smoking; and the level of incentive required to motivate smoking cessation in this population. This study aimed to estimate the financial threshold required to motivate fracture patients to stop smoking after injury.
\end{abstract}

Methods: This cross-sectional study utilized a discrete choice experiment (DCE) to elicit patient preferences towards financial incentives and reduced complications associated with smoking cessation. We presented participants with 12 hypothetical options with several attributes with varying levels. The respondents' data was used to determine the utility of each attribute level and the relative importance associated with each attribute.

Results: Of the 130 enrolled patients, 79\% reported an interest in quitting smoking. We estimated the financial incentive to be of greater relative importance (ri) (45\%) than any of the included clinical benefits of smoking cessations (deep infection (ri: 24\%), bone healing complications (ri: 19\%), and superficial infections (ri: 12\%)). A onetime payment of $\$ 800$ provided the greatest utility to the respondents $(0.64,95 \% \mathrm{Cl}: 0.36$ to 0.93$)$, surpassing the utility associated with a single $\$ 1000$ financial incentive $(0.36,95 \%$ Cl: 0.18 to 0.55$)$.

Conclusions: Financial incentives may be an effective tool to promote smoking cessation in the orthopaedic trauma population. The findings of this study define optimal payment thresholds for smoking cessation programs.

\footnotetext{
* Correspondence: nohara@som.umaryland.edu

${ }^{2}$ Department of Orthopaedics, University of Maryland School of Medicine,

110 South Paca St., Suite 300, Baltimore, MD, USA

Full list of author information is available at the end of the article
}

(c) The Author(s). 2021 Open Access This article is licensed under a Creative Commons Attribution 4.0 International License, which permits use, sharing, adaptation, distribution and reproduction in any medium or format, as long as you give appropriate credit to the original author(s) and the source, provide a link to the Creative Commons licence, and indicate if changes were made. The images or other third party material in this article are included in the article's Creative Commons licence, unless indicated otherwise in a credit line to the material. If material is not included in the article's Creative Commons licence and your intended use is not permitted by statutory regulation or exceeds the permitted use, you will need to obtain permission directly from the copyright holder. To view a copy of this licence, visit http://creativecommons.org/licenses/by/4.0/ The Creative Commons Public Domain Dedication waiver (http://creativecommons.org/publicdomain/zero/1.0/) applies to the data made available in this article, unless otherwise stated in a credit line to the data. 


\section{Background}

Smoking is associated with a wide range of complications in the orthopaedic trauma population [1-6]. Specifically, previous studies suggest that smoking and tobacco use may be associated with an increased risk of bone healing complications and infections [7-20]. Fortunately, the physiological effects of smoking and tobacco use observed after a fracture have been shown to be reversible within a short time frame. Smoking cessation during the early recovery phase can decrease the risk of these complications considerably, as both wound healing and the immune system improve within 6 weeks following cessation [21-23]. In three prospective randomized trials, perioperative smoking cessation demonstrated a $50 \%$ reduction in the risk of complications among successful quitters [24-26]. These findings may be particularly important in the orthopaedic trauma population, as complications frequently occur relatively within a few months after surgery.

Traditional smoking cessation interventions have demonstrated limited long-term success resulting in a quit rate of $5-10 \%$, with only $25 \%$ of smokers even utilizing the suggested programs [27, 28]. However, multi-modal interventions have shown a roughly doubled quit rate than single modality programs. Most combined interventions include various combinations of educational, behavioral, and pharmacologic components [29, 30].

Prior research suggests that financial incentives may be effective for smoking and tobacco use cessation [31-37]. A recent randomized trial compared smokers who received a one-time payment of $\$ 750$ with those who received smoking cessation information but no monetary incentive [38]. The trial demonstrated that cessation within the first 6 months nearly doubled, and enrollment in educational programs tripled with the addition of a financial incentive. In addition, the trial showed that financial incentives for smoking cessation significantly increased the rates of smoking cessation over 18 months. A 2019 systematic review suggests that financial incentives improve long-term smoking cessation rates in mixed population studies [39].

While these findings are critically important in the context of general health, in the orthopaedic trauma population, most smoking-related complications occur within the first year after injury $[1,2]$. Consequently, financial incentive programs may be especially beneficial if implemented early in the healing process to reverse the harmful health conditions associated with smoking during recovery from an orthopaedic injury.

The objectives of this study were to determine the willingness of orthopaedic trauma patients to accept a financial incentive to stop smoking after their fracture and quantify the level of financial incentive and clinical benefits required to motivate smoking cessation.
We hypothesized we would be able to model the utility of financial incentives and clinical benefits that would motivate patients to stop smoking after their fracture.

\section{Methods \\ Study design}

The study utilized a discrete choice experiment (DCE) to elicit patient preferences towards financial incentives and reduced complications associated with smoking cessation. DCEs are a well-established quantitative method that elicits stated preferences based on responses to described hypothetical scenarios. The response data are used to calculate the utility of each attribute level and the relative importance associated with each attribute [40-44]. Tradeoff estimates can also be calculated using the utility values. DCEs have been extensively used in the healthcare literature to elicit patient preferences $[45,46]$.

\section{Study setting and population}

This cross-sectional study was performed at a single Level 1 trauma center. The study has received ethical approval (HP-00083110) from the Institutional Review Board at the University of Maryland. The study included adult patients with a surgically treated extremity fracture and self-identified as a smoker. We excluded patients who were unable to speak and read English. Patients were enrolled at their postoperative clinic visits from January through August 2019. The median time from injury to consent for the survey was 50 days (IQR: 21-157).

\section{Survey development}

The survey presented 12 sets of hypothetical options, called choice sets, in which two potential clinical outcomes and an associated financial incentive were described (Fig. 1). The options described in the choice sets included possible financial incentives ranging from $\$ 0$ - \$1000, and clinical benefits, which included various risk levels for a nonunion, deep surgical site infection (SSI), and superficial SSI. Each choice set also had a "status quo" option, which provided no financial incentive, a $10 \%$ risk of nonunion, a $15 \%$ risk of a deep SSI, and a $20 \%$ risk of a superficial SSI (Table 2 in Appendix ). The size of the rewards and frequency were informed by a recent randomized trial that studied financial incentives for smoking cessation in the general population [38]. The risk attributes and their levels were designed based on patients' reported outcomes, consultation with orthopaedic trauma surgeons, and a literature review [7, 47-50]. The experiment design used a D-efficiency approach to maximize the orthogonality of the attributes and levels included in the 12 choice sets [51]. 
1. Of the three options, please select the one that you prefer?

\begin{tabular}{|c|c|c|c|}
\hline & $\begin{array}{c}\text { Quit Smoking - } \\
\text { Option } 1\end{array}$ & $\begin{array}{c}\text { Quit Smoking - } \\
\text { Option } 2\end{array}$ & $\begin{array}{l}\text { Continue } \\
\text { Smoking }\end{array}$ \\
\hline $\begin{array}{l}\text { One-time } \\
\text { payment }\end{array}$ & None & $\$ 1000$ & None \\
\hline $\begin{array}{l}\text { Risk of a bone } \\
\text { healing issue } \\
\text { needing } \\
\text { another } \\
\text { surgery }\end{array}$ & 8 out of 100 & 10 out of 100 & 10 out of 100 \\
\hline $\begin{array}{l}\text { Risk of a bone } \\
\text { infection } \\
\text { needing one or } \\
\text { more surgeries } \\
\text { to clean out } \\
\text { infection, } \\
\text { followed by } \underline{6} \\
\text { weeks of } \\
\underline{\text { antibiotics }}\end{array}$ & 6 out of 100 & 6 out of 100 & 15 out of 100 \\
\hline $\begin{array}{l}\text { Risk of a Skin } \\
\text { infection } \\
\text { needing } \\
\text { antibiotic pills } \\
\text { for } 2 \text { weeks }\end{array}$ & 5 out of 100 & 10 out of 100 & 20 out of 100 \\
\hline $\begin{array}{l}\text { Preferred } \\
\text { Option }\end{array}$ & $\square$ & $\square$ & $\square$ \\
\hline
\end{tabular}

Fig. 1 Sample choice set

\section{Survey Administration}

Consenting patients completed the paper-based DCE survey during a follow-up clinic visit. Prior to completing the survey, patients were informed that the objective of this study was to understand the willingness to quit smoking for a financial reward or a reduced risk of medical complications. The survey included a preamble describing the increased risk of a medical complication for smokers with injuries, as well as the recommendation that patients quit smoking to reduce their risk of these medical complications. The respondents were instructed that the hypothetical one-time payment would be provided if the patient abstained from smoking for 6 months after injury.
To ensure respondents understood the survey, we included an internal comprehension check in the design. One of the included choice sets had one option that was beneficial to the patient in all dimensions (financial incentive and postoperative complications). Selecting the inferior option for this choice set signified a failure to comprehend the survey, and the respondent's data were not included in the final analyses.

Demographic data included age, sex, race, education, income, health insurance status, and socioeconomic deprivation, as measured by the Area Deprivation Index (ADI). The ADI was developed by the Health Resources and Services Administration and represents a geographic area-based measure of the socioeconomic deprivation 
experienced by a neighborhood as a composite score of 17 variables, including income disparity and percent of the population age 25 and older with at least a high school diploma [52]. The survey also included questions on the participant's interest in quitting smoking and the available level of social support. We used these questions to explore heterogeneity in responses to financial rewards to smoking cessation.

\section{Statistical analysis}

There is no consensus on a sample size calculation for discrete choice experiments. However, previous research recommends 50 participants per subgroup in the analysis [40-42]. Based on this heuristic, 100 respondents would provide adequate power to model a binary subgroup.

The patient characteristics were described using counts with proportions for categorical data and means with standard deviations or medians with interquartile ranges for continuous variables, depending on the distribution. The DCE response data were effects coded and analyzed using a multinomial logit model [53]. We calculated each attribute's relative importance by dividing the $\log$ Worth (i.e., $-\log _{10}$ multiplied by the $p$-value of the likelihood ratio test) of the attribute by the sum of the LogWorths of the attributes included in the model $[54,55]$. The model parameter estimates denote the mean utility for a given level within each attribute. Willingness to pay values were used to determine the acceptable tradeoffs between a reduced financial incentive and the reduced risk of a postoperative complication. We assessed preference heterogeneity by adding covariates as interaction terms into the model. The covariates that we hypothesized to be associated with differential preferences included sex, high school education or less, an income less than the poverty level, and living in an area of high deprivation (ADI of 8 or higher). Interactions of $p<0.05$ were considered significant. We did not adjust our Type I error for the testing of multiple subgroups, and these results should be considered exploratory. Missing data were not imputed and were assumed to be missing completely at random. The analyses were performed with JMP Pro Version 14 (Cary, NC) and R Version 3.6.1 (Vienna, Austria).

\section{Results}

\section{Patients}

Of the 201 eligible patients, 130 (65\%) consented to participate in the study and completed the survey. An additional 16\% failed the survey's internal comprehension check and were excluded from the analysis. Of the 109 patients included in the final analyses, the mean age was 40 years (SD: 13$)$ and $66 \%(n=72)$ of the respondents were male (Table 1). The median household income was
$\$ 27,500$ (IQR: $\$ 5000-\$ 62,500$ ), and 38\% of the respondents had a high school education or less. Approximately one-third of the respondents were insured by Medicaid, and two-thirds of the respondents lived in neighborhoods with high levels of deprivation. Seventynine percent of the sample reported being interested in quitting smoking. Sixteen respondents (15\%) always selected the "neither" option, suggesting an unwillingness to quit smoking regardless of any benefit from a financial incentive or an increased risk of a postoperative complication. Fourteen respondents (13\%) consistently selected the option with a higher payment.

\section{Relative importance}

Of the included attributes, a financial incentive had the greatest relative importance to the respondents (relative importance (ri): 45\%) (Fig. 2). The risk of a deep infection ranked second (ri: 24\%). Bone healing complications (ri: 19\%) and superficial infections (ri: 12\%) were of lesser importance. When we excluded patients who were unwilling to stop smoking based on any presented options, the relative importance of the included attributes did not qualitatively change.

\section{Mean utility of attributes levels}

A one-time payment of $\$ 800$ provided the greatest utility to the respondents $(0.64,95 \% \mathrm{CI}: 0.36$ to 0.93$)$, surpassing the utility associated with a single $\$ 1000$ financial incentive $(0.36,95 \%$ CI: 0.18 to 0.55$)$ (Fig. 3a). Both the financial incentives of $\$ 800$ and $\$ 1000$ provided substantially more utility than a one-time incentive of $\$ 600$ or less. The gain in utility from no financial incentive to the $\$ 800$ incentive (mean difference (md): $1.2,95 \% \mathrm{CI}$ : -1.6 to -0.9$)$ was greater than the utility lost when one's risk of a deep SSI (md: 1.1, 95\% CI: -1.4 to -0.8 ), bone healing complication (md: $0.7,95 \% \mathrm{CI}:-0.9$ to 0.4 ), or superficial SSI (md: $-0.6,95 \%$ CI: -0.8 to -0.3 ) declined within the scale included in the experiment. When we excluded patients who were unwilling to stop smoking based on any presented options, the effects were marginally increased (Fig. 3b).

\section{Willingness to pay}

We used willingness to pay estimates to determine the value associated with a $1 \%$ decrease in the risk of a postoperative complication. Based on the respondents, patients would forgo $\$ 84$ (95\% CI: $\$ 56$ to $\$ 112$ ) of the financial incentive for a $1 \%$ decline in their risk of a bone healing complication. Similarly, respondents would forgo $\$ 77$ (95\% CI: $\$ 53$ to $\$ 101)$ of the financial incentive for a $1 \%$ decline in their risk of a deep SSI and \$36 (95\% CI: $\$ 22$ to $\$ 49$ ) of the financial incentive for a $1 \%$ decline in their risk of a superficial SSI. 
Table 1 Patient characteristics $(n=109)$

\begin{tabular}{|c|c|c|}
\hline \multicolumn{2}{|l|}{ Age, mean (SD) } & $40.4(13.0)$ \\
\hline \multicolumn{2}{|l|}{ Sex, male, n (\%) } & $72(66)$ \\
\hline \multicolumn{3}{|l|}{ Race, n (\%) } \\
\hline & White & $55(50)$ \\
\hline & African-American & $42(39)$ \\
\hline & Other & $11(10)$ \\
\hline \multicolumn{3}{|l|}{ Educational attainment, $\mathrm{n}(\%)^{\mathrm{a}}$} \\
\hline & High school or less & $41(38)$ \\
\hline & Some college or degree & $68(62)$ \\
\hline \multicolumn{2}{|l|}{ Household income, median (IQR) ${ }^{b}$} & $\$ 27,500(\$ 5000-\$ 62,500$ \\
\hline \multicolumn{3}{|l|}{ Health insurance, n (\%) } \\
\hline & Medicaid & $39(36)$ \\
\hline & Medicare & $32(29)$ \\
\hline & Private employer-based & $23(21)$ \\
\hline & Other public insurance & $12(11)$ \\
\hline & Uninsured & $3(3)$ \\
\hline \multicolumn{3}{|l|}{ Area deprivation index, $\mathrm{n}(\%)^{c}$} \\
\hline & Top quartile & $17(16)$ \\
\hline & 2nd quartile & $18(17)$ \\
\hline & 3rd quartile & $35(33)$ \\
\hline & Lowest quartile & $37(35)$ \\
\hline \multicolumn{2}{|l|}{ Interested in quitting, n (\%) } & $86(79)$ \\
\hline \multicolumn{3}{|c|}{ Social/emotional support available, $\mathrm{n}(\%)^{\mathrm{d}}$} \\
\hline & Always & $46(42)$ \\
\hline & Usually & $19(17)$ \\
\hline & Sometimes & $27(25)$ \\
\hline & Rarely & $10(9)$ \\
\hline & Never & $4(4)$ \\
\hline
\end{tabular}

Abbreviation: IQR Interquartile range

${ }^{\text {a }}$ One participant refused to answer question

b 25 participants refused to answer question

c Two participants had out of state addresses

d Three participants refused to answer question

\section{Heterogeneity in preferences}

We tested several covariates, including sex, education, income, and neighborhood deprivation, for possible heterogeneity in preferences. None of these covariates met the $p<0.05$ threshold when added as interaction terms into the model.

\section{Discussion}

Our findings suggest that an $\$ 800$ one-time payment may adequately incentivize short-term smoking cessation in orthopaedic trauma patients. The benefits of the financial incentive were of greater importance to the respondents than the clinical benefits of smoking cessation. The preference for the financial incentive was homogenous across the sample.
It is possible that an $\$ 800$ financial incentive was more desirable to patients than $\$ 1000$ due to a loss in intrinsic motivation with a payout that exceeds a certain threshold. Behavioral economics describes a crowding out phenomenon in which increasing extrinsic motivation, such as financial incentives, reduces intrinsic motivation to act on one's own [56]. There is limited evidence that motivation crowding out occurs in health-related behaviors [57], but this effect is difficult to evaluate and has not been previously studied with respect to various levels of financial incentives for smoking cessation to our knowledge.

Seventy-nine percent of the respondents stated an interest in smoking cessation prior to completing the DCE. A previous study at our institutions found that 


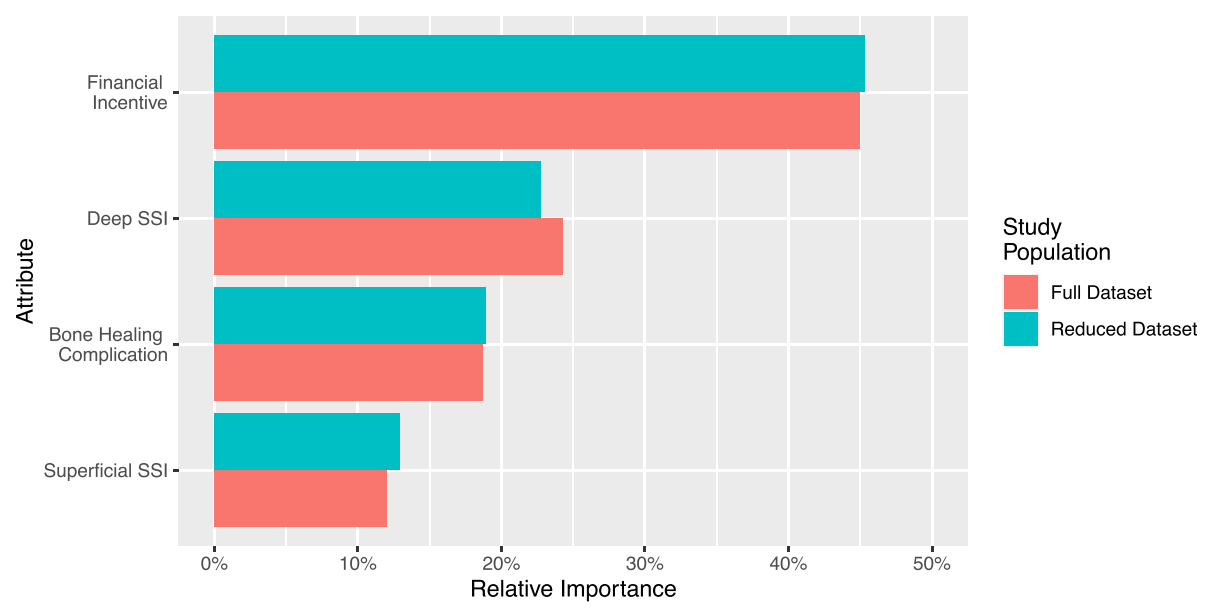

Fig. 2 The relative importance of the included attributes calculated with the full sample and with a reduced sample that excluded patients that were unwilling to stop smoking based on any of the presented options. SSI, surgical site infection

$48 \%$ of smokers that sustained a traumatic orthopaedic injury stated that their injury made them more likely to quit [58]. If we assume the $35 \%$ of eligible participants that refused to participate in the DCE also had limited interest in smoking cessation, the findings are relatively consistent. However, the link between an injury and the willingness to quit smoking requires further exploration. The time of injury may represent an opportunity for attitudinal change and associated with a shift in the valuation of habits and well-being [59-62].

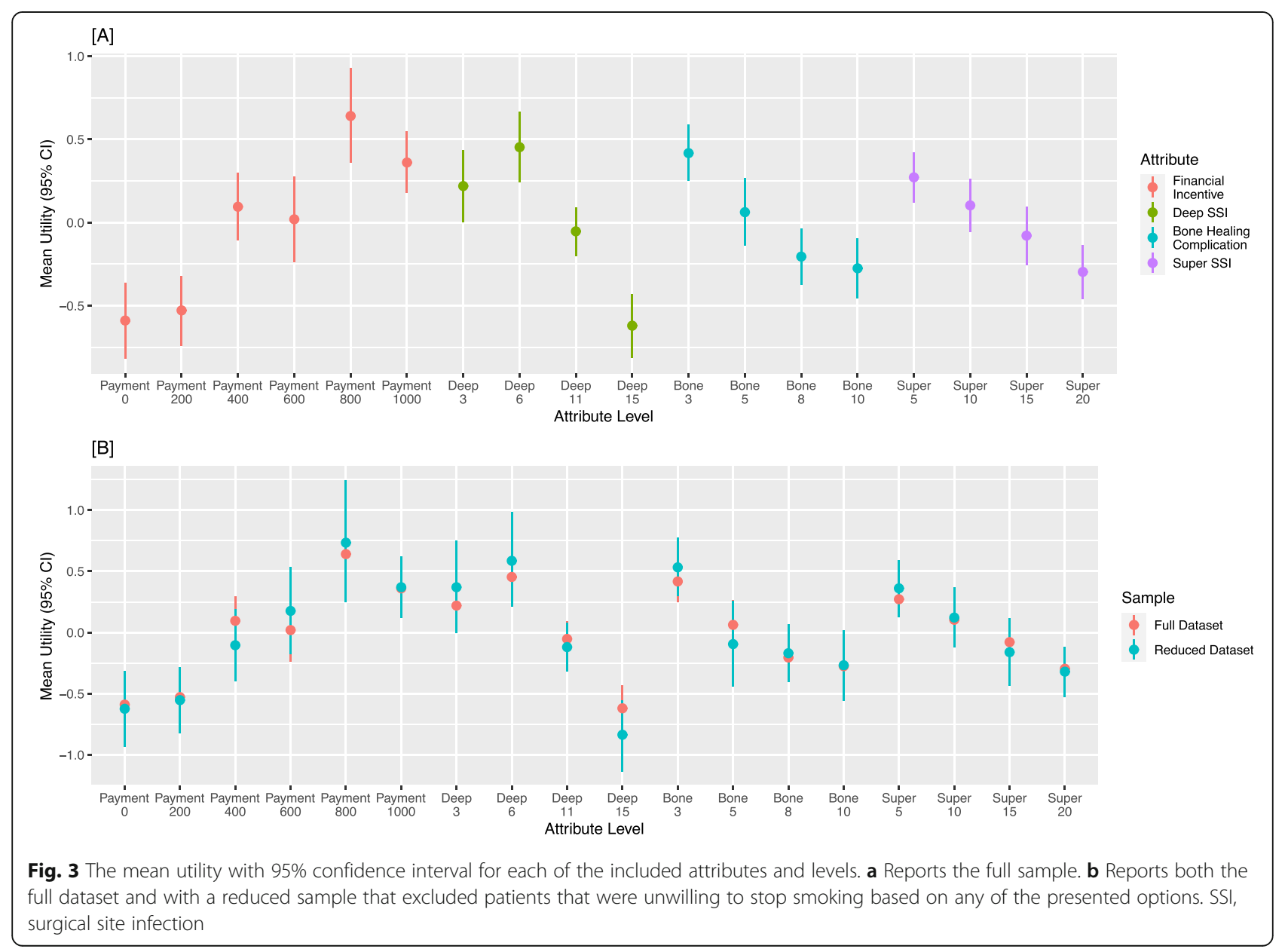


Research suggests that smoking is more than twice as prevalent in the orthopaedic trauma population than the general US population, with rates approximating 50\% compared to $20 \%$, respectively [63, 64]. The epidemiological burden of smoking in orthopaedic trauma patients may be further exasperated by socioeconomic conditions. Our sample and the broader literature indicate the smoking population has a generally lower socioeconomic status $[64,65]$. The median annual household income in our sample was $\$ 27,500$. This measure is considerably lower than the median income for the US State of Maryland, where the study was conducted, which stands at $\$ 83,242$ according to the 2018 American Community Survey [66]. Data from the US Department of Health and Human Services and the Administration of Substance Abuse and Mental Health Services supports this finding, noting that smoking is more common in individuals living below the poverty level $[64,65]$. While we did not observe heterogeneity in preferences for financial incentives based on pre-injury household income, we also had few respondents with pre-injury household incomes above the state median to adequately test heterogeneity on this covariate. However, consistency in intervention effect across various demographic characteristics was also observed in another trial providing financial incentives to quit smoking [38]. The evaluation of financial incentive programs in patients after an orthopaedic injury is required to assess if these stated preferences remain robust across various demographic and socioeconomic characteristics.

Thirty-five percent of eligible participants declined to complete the survey. This rate of refusal could be attributed to disinterest in research, inconvenience, or resistance to quitting. Of note, we did not compensate respondents for completing the survey, and participant interest may be higher for an actual financial incentive program. In the study, $15 \%$ of respondents indicated an unwillingness to quit smoking regardless of the benefits from a financial incentive or protection against postoperative complications.

To our knowledge, this study is the first to investigate orthopaedic trauma patient preferences for financial incentives to stop smoking. The strengths of this study include actionable findings for smoking cessation programs or the design for future trials. The sample size was sufficient for precise utility estimates. The characteristics of the patient population were similar to prior smoking cessation studies in orthopaedic trauma patients $[7,16]$.

The study had several limitations. Patients consented for the survey in their postoperative follow-up appointments, and the results may not be consistent with preferences immediately after injury. Variation in the timing of the proposed payment was not assessed as part of this study. A recent clinical trial suggests the combination of a prepaid and promised incentive to be most efficient in increasing smoking quit rates [67]. Future research considers how to optimize the timing of financial incentives relative to injury. Complications experienced by patients may affect their preferences for payment and willingness to quit smoking. This study did not analyze preferences based on complication occurrence, but we recommend future research address this. We did not observe substantial variation in preferences based on characteristics, such as sex, race, education, income, and neighborhood deprivation. These null findings may be due to our limited sample and a narrow distribution of covariates, such as income, within the sample. Our study was performed at one center, so the generalizability of our findings to other patient groups is unknown and awaits confirming research. Finally, we did not measure the intrinsic motivation of the patients to quit smoking and are unable to assess the impact of that covariate on our estimates.

Our data suggest that orthopaedic trauma patients are willing to quit smoking during recovery for a financial incentive. These findings are consistent with those reported in the literature [34.38]. It is possible that in the short-term, extrinsic motivation to stop smoking coming from monetary payment does not crowd out intrinsic effort. In the long-run, habits and lack of self-control may cause relapse in these patients and reduce the effect of monetary rewards.

\section{Conclusions}

Financial incentives may be an effective tool to promote smoking cessation in the orthopaedic trauma population if proven cost-effective. More research on the costeffectiveness of financial incentive programs to prevent harmful health conditions is needed to justify policies and third-party funding for incentive programs [68]. The findings of our study define optimal payment thresholds for smoking cessation programs in a US study population. In the context of patient-centered research, it is central that we consider patient preferences when implementing smoking cessation interventions to improve intake and acceptance. Financial incentive programs to stop smoking in the short-term hold a promise to improve outcomes and reduce cost in the orthopaedic trauma population. Future studies applying financial incentives to promote smoking cessation should integrate patient preferences in the design and implementation of these programs.

Acknowledgements

We thank the patients that participated in the study.

\section{Authors' contributions}

All authors contributed to the design of the study. DA and NNO wrote the draft manuscript with input from all authors. JA and KO collected the data. NNO analyzed the data with assistance from DA, JA, and AJT. All authors provided critical review of the manuscript and final approval of the version to be submitted for publication. NNO is the guarantor for the overall content. 


\section{Appendix}

Table $\mathbf{2}$ Table of attributes and levels included in the discrete choice experiment

\begin{tabular}{ll}
\hline Attribute & Levels \\
\hline Financial incentive & $\$ 0, \$ 200, \$ 400, \$ 600, \$ 800, \$ 1000$ \\
Nonunion: Risk of a bone healing issue needing another surgery & $3,5,8,10 \%$ \\
$\begin{array}{l}\text { Deep infection: Risk of a bone infection needing one or more surgeries to clean out infection, } \\
\text { followed by } 6 \text { weeks of antibiotics }\end{array}$ & $3,6,11,15 \%$ \\
Superficial infection: Risk of a skin infection needing antibiotic pills for 2 weeks & $5,10,15,20 \%$
\end{tabular}

\section{Funding}

The study did not receive external funding

\section{Availability of data and materials}

The study data will be made available upon written request to the corresponding author.

\section{Declarations}

\section{Ethics approval and consent to participate}

This study was approved by the University of Maryland Baltimore Institutional Review Board (HP-00083110) and has been performed in accordance with the ethical standards of the Declaration of Helsinki. Informed consent was obtained from all participants included in the study.

\section{Consent for publication}

Not appliable.

\section{Competing interests}

Dr. OToole reports consults not related to this study from Smith \& Nephew, Lincotek, and Imagen; and stock options not related to this study from Imagen. No other authors have potential conflicts of interest to disclose.

\section{Author details}

${ }^{1}$ Department of Health Policy and Management, Johns Hopkins Bloomberg School of Public Health, Baltimore, MD, USA. ${ }^{2}$ Department of Orthopaedics, University of Maryland School of Medicine, 110 South Paca St., Suite 300, Baltimore, MD, USA. ${ }^{3}$ Department of International Health, Johns Hopkins Bloomberg School of Public Health, Baltimore, MD, USA.

\section{Received: 27 October 2020 Accepted: 18 April 2021}

Published online: 26 April 2021

\section{References}

1. Scolaro JA, Schenker ML, Yannascoli S, Baldwin K, Mehta S, Ahn J. Cigarette smoking increases complications following fracture: a systematic review. J Bone Joint Surg Am. 2014;96(8):674-81. https://doi. org/10.2106/JBJS.M.00081.

2. Bedard NA, DeMik DE, Owens JM, Glass NA, DeBerg J, Callaghan JJ. Tobacco use and risk of wound complications and periprosthetic joint infection: a systematic review and meta-analysis of primary total joint arthroplasty procedures. J Arthroplasty. 2019;34(2):385-396.e4.

3. Pearson RG, Clement RG, Edwards KL, Scammell BE. Do smokers have greater risk of delayed and non-union after fracture, osteotomy and arthrodesis? A systematic review with meta-analysis. BMJ Open. 2016;6(11): e010303-2015-010303. https://doi.org/10.1136/bmjopen-2015-010303.

4. Lee JJ, Patel R, Biermann JS, Dougherty PJ. The musculoskeletal effects of cigarette smoking. J Bone Joint Surg Am. 2013;95(9):850-9. https://doi.org/1 0.2106/JBJS.L.00375

5. Beahrs TR, Reagan J, Bettin CC, Grear BJ, Murphy GA, Richardson DR. Smoking effects in foot and ankle surgery: an evidence-based review. Foot Ankle Int. 2019;40(10):1226-32. https://doi.org/10.1177/1071100719867942.

6. Bettin CC, Gower K, McCormick K, Wan JY, Ishikawa SN, Richardson DR, et al. Cigarette smoking increases complication rate in forefoot surgery. Foot Ankle Int. 2015;36(5):488-93. https://doi.org/10.1177/1071100714565785.

7. Castillo RC, Bosse MJ, MacKenzie EJ, Patterson BM, LEAP Study Group. Impact of smoking on fracture healing and risk of complications in limb- threatening open tibia fractures. J Orthop Trauma. 2005;19(3):151-7. PMID: 15758667. https://doi.org/10.1097/00005131-200503000-00001.

8. Kyro A, Usenius JP, Aarnio M, Kunnamo I, Avikainen V. Are smokers a risk group for delayed healing of tibial shaft fractures? Ann Chir Gynaecol. 1993; 82(4):254-62.

9. Enninghorst N, McDougall D, Hunt JJ, Balogh ZJ. Open tibia fractures: timely debridement leaves injury severity as the only determinant of poor outcome. J Trauma. 2011;70(2):352-6 discussion 356-7.

10. Giannoudis PV, MacDonald DA, Matthews SJ, Smith RM, Furlong AJ, De Boer $P$. Nonunion of the femoral diaphysis. The influence of reaming and nonsteroidal anti-inflammatory drugs. J Bone Joint Surg Br. 2000;82(5):655-8. https://doi.org/10.1302/0301-620X.82B5.0820655.

11. Harvey EJ, Agel J, Selznick HS, Chapman JR, Henley MB. Deleterious effect of smoking on healing of open tibia-shaft fractures. Am J Orthop (Belle Mead NJ). 2002;31(9):518-21.

12. Moghaddam A, Zimmermann G, Hammer K, Bruckner T, Grutzner PA, von Recum J. Cigarette smoking influences the clinical and occupational outcome of patients with tibial shaft fractures. Injury. 2011;42(12):1435-42. https://doi.org/10.1016/j.injury.2011.05.011.

13. Ristiniemi J, Flinkkila T, Hyvonen P, et al. Two-ring hybrid external fixation of distal tibial fractures: a review of 47 cases. J Trauma. 2007;62(1):174-83. https://doi.org/10.1097/01.ta.0000215424.00039.3b.

14. Taitsman LA, Lynch JR, Agel J, Barei DP, Nork SE. Risk factors for femoral nonunion after femoral shaft fracture. J Trauma. 2009;67(6):1389-92. https:// doi.org/10.1097/TA.0b013e318182afd0.

15. Ziran BH, Hendi P, Smith WR, Westerheide K, Agudelo JF. Osseous healing with a composite of allograft and demineralized bone matrix: adverse effects of smoking. Am J Orthop (Belle Mead NJ). 2007;36(4):207-9.

16. Nasell H, Ottosson C, Tornqvist H, Linde J, Ponzer S. The impact of smoking on complications after operatively treated ankle fractures--a follow-up study of 906 patients. J Orthop Trauma. 2011;25(12):748-55. https://doi.org/10.1 097/BOT.0b013e318213f217.

17. Kurtz SM, Lau EC, Ong KL, Adler EM, Kolisek FR, Manley MT. Which clinical and patient factors influence the national economic burden of hospital readmissions after total joint arthroplasty? Clin Orthop Relat Res. 2017; 475(12):2926-37. https://doi.org/10.1007/s11999-017-5244-6.

18. Kapadia BH, McElroy MJ, Issa K, Johnson AJ, Bozic KJ, Mont MA. The economic impact of periprosthetic infections following total knee arthroplasty at a specialized tertiary-care center. J Arthroplast. 2014;29(5): 929-32. https://doi.org/10.1016/j.arth.2013.09.017.

19. Heyes G, Weigelt L, Molloy A, Mason L. The influence of smoking on foot and ankle surgery: a review of the literature. Foot (Edinb). 2020:101735. https://doi. org/10.1016/j.foot.2020.101735 Epub ahead of print. PMID: 33168350.

20. Westgeest J, Weber D, Dulai SK, Bergman JW, Buckley R, Beaupre LA. Factors associated with development of nonunion or delayed healing after an open long bone fracture: a prospective cohort study of 736 subjects. J Orthop Trauma. 2016;30(3):149-55. 26544953. https://doi.org/10.1097/BOT. 0000000000000488

21. Hersey P, Prendergast $D, E d w a r d s ~ A$. Effects of cigarette smoking on the immune system. Follow-up studies in normal subjects after cessation of smoking. Med J Aust. 1983;2(9):425-9. https://doi.org/10.5694/j.1326-5377.1 983.tb122565.x.

22. Warner DO. Perioperative abstinence from cigarettes: physiologic and clinical consequences. Anesthesiology. 2006;104(2):356-67. https://doi.org/1 0.1097/00000542-200602000-00023.

23. Mills E, Eyawo O, Lockhart I, Kelly S, Wu P, Ebbert JO. Smoking cessation reduces postoperative complications: A systematic review and metaanalysis. Am J Med. 2011;124(2):144-154.e8. 
24. Nåsell H, Adami J, Samnegård E, Tønnesen H, Ponzer S. Effect of smoking cessation intervention on results of acute fracture surgery: a randomized controlled trial. J Bone Joint Surg Am. 2010;92(6):1335-42. https://doi.org/1 0.2106/JBJS.I.00627 PMID: 20516308

25. Sorensen LT, Karlsmark T, Gottrup F. Abstinence from smoking reduces incisional wound infection: a randomized controlled trial. Ann Surg. 2003; 238(1):1-5.

26. Lindstrom D, Sadr Azodi O, Wladis A, et al. Effects of a perioperative smoking cessation intervention on postoperative complications: a randomized trial. Ann Surg. 2008;248(5):739-45. https://doi.org/10.1097/SLA. Ob013e3181889d0d.

27. Shiffman S, Brockwell SE, Pillitteri JL, Gitchell JG. Use of smoking-cessation treatments in the United States. Am J Prev Med. 2008;34(2):102-11. https:// doi.org/10.1016/j.amepre.2007.09.033.

28. 2008 PHS Guideline Update Panel. Liaisons, and Staff. Treating tobacco use and dependence: 2008 update U.S. public health service clinical practice guideline executive summary. Respir Care. 2008;53(9):1217-22

29. Jorenby DE, Leischow SJ, Nides MA, Rennard SI, Johnston JA, Hughes AR, et al. A controlled trial of sustained-release bupropion, a nicotine patch, or both for smoking cessation. N Engl J Med. 1999;340(9):685-91. https://doi. org/10.1056/NEJM199903043400903.

30. Stead LF, Lancaster T. Combined pharmacotherapy and behavioural interventions for smoking cessation. Cochrane Database Syst Rev. 2012;10: CD008286.

31. Fanshawe TR, Hartmann-Boyce J, Perera R, Lindson N. Competitions for smoking cessation. Cochrane Database Syst Rev. 2019;2:CD013272.

32. Witman A, Acquah J, Alva M, Hoerger T, Romaire M. Medicaid incentives for preventing chronic disease: effects of financial incentives for smoking cessation. Health Serv Res. 2018;53(6):5016-34. https://doi.org/10.1111/14756773.12994.

33. Sigmon SC, Patrick ME. The use of financial incentives in promoting smoking cessation. Prev Med. 2012;55(Suppl):S24-32. https://doi.org/10.101 6/j.ypmed.2012.04.007

34. Halpern SD, French B, Small DS, Saulsgiver K, Harhay MO, AudrainMcGovern J, et al. Randomized trial of four financial-incentive programs for smoking cessation. N Engl J Med. 2015;372(22):2108-17. https://doi.org/10.1 056/NEJMoa1414293.

35. Etter JF, Schmid F. Effects of large financial incentives for long-term smoking cessation: a randomized trial. J Am Coll Cardiol. 2016;68(8):777-85. https://doi.org/10.1016/j.jacc.2016.04.066.

36. Ladapo JA, Tseng CH, Sherman SE. Financial incentives for smoking cessation in hospitalized patients: a randomized clinical trial. Am J Med. 2020;133(6):741-9. https://doi.org/10.1016/j.amjmed.2019.12.025 Epub 2020 Jan 23. PMID: $31982494 ;$ PMCID: PMC7293955.

37. Team DTB. Financial incentives improve rates of sustained smoking cessation in the workplace. Drug Ther Bull. 2019;57(1):8. https://doi.org/1 0.1136/dtb.2018.000056. PMID: 30567851.

38. Volpp KG, Troxel AB, Pauly MV, Glick HA, Puig A, Asch DA, et al. A randomized, controlled trial of financial incentives for smoking cessation. N Engl J Med. 2009;360(7):699-709. https://doi.org/10.1056/NEJMsa0806819.

39. Notley C, Gentry S, Livingstone-Banks J, Bauld L, Perera R, Hartmann-Boyce J. Incentives for smoking cessation. Cochrane Database Syst Rev. 2019;7(7): CD004307. https://doi.org/10.1002/14651858.CD004307.pub6 PMID: 31313293; PMCID: PMC6635501.

40. Luyten J, Kessels R, Goos P, et al. Public preferences for prioritizing preventive and curative health care interventions: a discrete choice experiment. Value Health. 2015;18:224-33 26.

41. Ryan M, Farrar S. Using conjoint analysis to elicit preferences for health care. BMJ. 2000;320(7248):1530-3. https://doi.org/10.1136/bmj.320.7248.1530.

42. Cheraghi-Sohi S, Hole AR, Mead N, McDonald R, Whalley D, Bower P, et al. What patients want from primary care consultations: a discrete choice experiment to identify patients' priorities. Ann Fam Med. 2008;6(2):107-15. https://doi.org/10.1370/afm.816

43. Dietrich JJ, Atujuna M, Tshabalala G, Hornschuh S, Mulaudzi M, Koh M, et al. A qualitative study to identify critical attributes and attribute-levels for a discrete choice experiment on oral pre-exposure prophylaxis (PrEP) delivery among young people in Cape Town and Johannesburg, South Africa. BMC Health Serv Res. 2021;21(1):17. https://doi.org/10.1186/s12913-020-05942-8 PMID: 33407395; PMCID: PMC7788832.

44. Monnette A, Chen E, Hong D, Bazzano A, Dixon S, Arnold WD, et al. Treatment preference among patients with spinal muscular atrophy (SMA): a discrete choice experiment. Orphanet J Rare Dis. 2021;16(1):36. https://doi. org/10.1186/s13023-020-01667-3 PMID: 33472673; PMCID: PMC7819167.

45. Ryan M. Discrete choice experiments in health care. BMJ. 2004;328(7436): 360-1. https://doi.org/10.1136/bmj.328.7436.360 PMID: 14962852; PMCID: PMC341374.

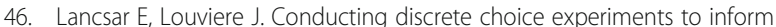
healthcare decision making. Pharmacoeconomics. 2008;26(8):661-77. https://doi.org/10.2165/00019053-200826080-00004.

47. Sun $Y$, Wang $H$, Tang $Y$, Z Zhao $H$, Qin $S$, Xu L, et al. Incidence and risk factors for surgical site infection after open reduction and internal fixation of ankle fracture: a retrospective multicenter study. Medicine (Baltimore). 2018;97(7): e9901. https://doi.org/10.1097/MD.0000000000009901 PMID: 29443762; PMCID: PMC5839807.

48. Norris GR, Checketts JX, Scott JT, Vassar M, Norris BL, Giannoudis PV. Prevalence of deep surgical site infection after repair of periarticular knee fractures: a systematic review and meta-analysis. JAMA Netw Open. 2019; 2(8):e199951. https://doi.org/10.1001/jamanetworkopen.2019.9951 Erratum in: JAMA Netw Open. 2019 Oct 2;2(10):e1913513. PMID: 31441940; PMCID: PMC6714463.

49. Ekegren CL, Edwards ER, de Steiger R, Gabbe BJ. Incidence, costs and predictors of non-union, delayed union and mal-union following long bone fracture. Int J Environ Res Public Health. 2018;15(12):2845. https://doi.org/1 0.3390/ijerph15122845 PMID: 30551632; PMCID: PMC6313538.

50. Papakonstantinou MK, Hart MJ, Farrugia R, Gosling C, Kamali Moaveni A, van Bavel $D$, et al. Prevalence of non-union and delayed union in proximal humeral fractures. ANZ J Surg. 2017;87(1-2):55-9. https://doi.org/10.1111/a ns.13756 Epub 2016 Sep 12. PMID: 27619072.

51. Kuhfeld WF, Tobias RD, Garratt M. Efficient experimental design with marketing research applications. J Mark Res. 1994 Nov;31(4):545-57. https:// doi.org/10.1177/002224379403100408.

52. Kind AJH, Buckingham WR. Making neighborhood-disadvantage metrics accessible - the neighborhood atlas. N Engl J Med. 2018:378(26):2456-8

53. Train KE. Discrete choice methods and simulation. 2nd ed: Cambridge University Press; 2009

54. Luyten J, Kessels R, Atkins KE, Jit M, van Hoek AJ. Quantifying the public's view on social value judgments in vaccine decision-making: a discrete choice experiment. Soc Sci Med. 2019;228:181-93. https://doi.org/10.1016/j. socscimed.2019.03.025 Epub 2019 Mar 20. PMID: 30925392.

55. Hoogink J, Verelst F, Kessels R, van Hoek AJ, Timen A, Willem L, et al. Preferential differences in vaccination decision-making for oneself or one's child in The Netherlands: a discrete choice experiment. BMC Public Health. 2020;20(1):828. https://doi.org/10.1186/s12889-020-08844-w PMID: 32487041; PMCID: PMC7268356.

56. Weibel A, Rost K, Osterloh M. Pay for performance in the public sector benefits and (hidden) costs. J Public Adm Res Theory. 2010;20(2):397-412.

57. Promberger M, Marteau TM. When do financial incentives reduce intrinsic motivation? comparing behaviors studied in psychological and economic literatures. Health Psychol. 2013;32(9):950-7. https://doi.org/10.1037/a003272 7 Erratum in: Health Psychol. 2013 Nov;32(11):1148. PMID: 24001245; PMCID: PMC3906839.

58. Matuszewski PE, O'Toole RV, Boulton CL. Do smokers know smoking is bad for fracture healing? Minneapolis, MN: Orthopaedic trauma Association Annual Meeting; 2012

59. Baron MD, DeFrancesco CJ, Liu TC, Leone FT, Ahn J. A teachable moment after Orthopaedic fracture in the smoking patient: a randomized, controlled trial. J Orthop Trauma. 2017;31(8):e252-4. https://doi.org/10.1097/BOT. 0000000000000841 PMID: 28737593.

60. Matuszewski PE, Boulton CL, O'Toole RV. Orthopaedic trauma patients and smoking: knowledge deficits and interest in quitting. Injury. 2016;47(6): 1206-11. https://doi.org/10.1016/j.injury.2016.03.018 Epub 2016 Apr 8. PMID: 27090096.

61. Neptune D, Bonevski B, Enninghorst N, Balogh ZJ. The prevalence of smoking and interest in quitting among surgical patients with acute extremity fractures. Drug Alcohol Rev. 2014;33(5):548-54. https://doi.org/1 0.1111/dar.12170 Epub 2014 Aug 5. PMID: 25091934

62. Kahneman D, Ritov I, Schkade D. Economic preferences or attitude expressions? An analysis of Dollar responses to public issues. J Risk Uncertain. 1999:19(1-3):203-35. https://doi.org/10.1023/A:1007835629236.

63. Centers for Disease Control and Prevention. Current cigarette smoking among Adults-United states, 2005-2012. Morb Mortal Wkly Rep. 2014; 63(02):29-34. 
64. U.S. Department of Health and Human Services. The Health Consequences of Smoking - 50 Years of Progress: A Report of the Surgeon General. Atlanta: U.S. Department of Health and Human Services, Centers for Disease Control and Prevention, National Center for Chronic Disease Prevention and Health Promotion, Office on Smoking and Health; 2014. accessed 2016 Jun 13

65. Abuse S, Administration MHS. Results from the 2016 National Survey on drug use and health: detailed tables. Rockville, MD: Substance Abuse and Mental Health Services Administration, Center for Behavioral Health Statistics and Quality; 2014. accessed 2018 Jul 12

66. US Census Bureau, 2017 And 2018 American community survey. Accessed online: https://www.census.gov/library/stories/2019/09/us-medianhousehold-income-up-in-2018-from-2017.html\# [accessed 2020 Aug 29].

67. Cheung YTD, Weng X, Wang MP, Ho SY, Kwong ACS, Lai WWY, et al. Effect of prepaid and promised financial incentive on follow-up survey response in cigarette smokers: a randomized controlled trial. BMC Med Res Methodol. 2019;19(1):138. https://doi.org/10.1186/s12874-019-0786-9 PMID: 31272393; PMCID: PMC6610937.

68. Finkelstein EA, Bilger M, Baid D. Effectiveness and cost-effectiveness of incentives as a tool for prevention of non-communicable diseases: a systematic review. Soc Sci Med. 2019;232:340-50. https://doi.org/10.1016/j. socscimed.2019.05.018 Epub 2019 May 17. PMID: 31129504.

\section{Publisher's Note}

Springer Nature remains neutral with regard to jurisdictional claims in published maps and institutional affiliations.

Ready to submit your research? Choose BMC and benefit from:

- fast, convenient online submission

- thorough peer review by experienced researchers in your field

- rapid publication on acceptance

- support for research data, including large and complex data types

- gold Open Access which fosters wider collaboration and increased citations

- maximum visibility for your research: over $100 \mathrm{M}$ website views per year

At BMC, research is always in progress.

Learn more biomedcentral.com/submissions 